\title{
Hyperosmolarity Deserves More Attention in Critically III COVID-19 Patients with Diabetes: A Cohort-Based Study
}

This article was published in the following Dove Press journal: Diabetes, Metabolic Syndrome and Obesity: Targets and Therapy

\author{
Luoning Gou',* \\ Ming Xiang ${ }^{2, *}$ \\ Xiao $\operatorname{Ran}^{3, *}$ \\ Fen Wang' \\ Shujun Zhang' \\ Shusheng $\mathrm{Li}^{3}$ \\ Kun Dong' \\ Xi Chen' \\ Yangxin Huang ${ }^{4}$ \\ Chengzhen Meng ${ }^{2}$ \\ Qian Fan ${ }^{2}$ \\ Yan Yang' \\ Xuefeng Yu' \\ Delin Ma' \\ Ping Yin ${ }^{2}$
}

'Department of Endocrinology, Tongji Hospital, Tongji Medical College, Huazhong University of Science and Technology, Wuhan, People's

Republic of China; ${ }^{2}$ Department of Epidemiology and Biostatistics, School of Public Health, Tongji Medical College, Huazhong University of Science and Technology, Wuhan, People's Republic of China; ${ }^{3}$ Department of Emergency Medicine, Tongji Hospital, Tongji Medical College,

Huazhong University of Science and Technology, Wuhan, People's Republic of China; ${ }^{4}$ College of Public Health, University of South Florida,

Tampa, Florida, The United States

*These authors contributed equally to this work

Correspondence: Ping Yin; Delin Ma Tongji Medical College, Huazhong University of Science and Technology, 13 Hongkong Road, Wuhan, 430030 Hubei,

People's Republic of China

$\mathrm{Tel}+86-27-83692832$

Fax +86-27-83692333

Email pingyin2000@I26.com

Delin Ma

Email maderine4@I63.com
Purpose: Recently, a cluster of pneumonia caused by SARS-CoV-2 were identified in Wuhan and spread throughout the world. More information about risk factors for mortality of critically ill patients infected with SARS-CoV-2 remain to be evaluated.

Methods: We included adult patients confirmed with SARS-CoV-2 infection who were critically ill and admitted to the intensive care unit (ICU) of Tongji Hospital in Wuhan from Feb 4, 2020 to Feb 20, 2020. Data were collected and compared between patients who died and improved. Logistic regression was used to explore the risk factors for death of SARSCoV-2-infected critically ill patients.

Results: A total of 160 critically ill patients with SARS-CoV-2 infection were included, of which 146 patients with appeared outcomes were included into the final analysis. The random blood glucose, serum sodium and effective plasma osmolarity were higher in deceased patients, especially in patients with diabetes. There were 7 patients with diabetes with hyperosmolar status and all of them were deceased. Multivariable regression revealed that older age (odds ratio 4.28, 95\% CI 1.01-18.20; $\mathrm{p}=0.049$ ), higher C-reactive protein (odds ratio 1.01, 1.00-1.03; $\mathrm{p}=0.024$ ), higher interleukin-6 (odds ratio 1.01, 1.00-1.03; $\mathrm{p}=$ 0.0323 ), and $\mathrm{d}$-dimer greater than $1 \mu \mathrm{g} / \mathrm{mL}$ (odds ratio $1.10,1.01-1.20 ; \mathrm{p}=0.032$ ) at admission were associated with increased odds of death.

Conclusion: In conclusion, hyperosmolarity needs more attention and may contribute to mortality in critically ill patients with COVID-19, especially in those with diabetes. Older age, inflammatory response, and thrombosis may be risk factors for death of critically ill patients with SARS-CoV-2 infection.

Keywords: SARS-CoV-2, critically ill, hyperosmolarity, diabetes, risk factors, mortality

\section{Introduction}

In early December 2019, the first pneumonia cases of unknown cause were identified in Wuhan, Hubei province in China. ${ }^{1}$ A novel betacoronavirus, that is currently named severe acute respiratory syndrome coronavirus 2 (SARS-CoV-2), was identified as the pathogen through high-throughput sequencing of respiratory tract samples of patients. ${ }^{2,3}$ Several evidences pointed out that SARS-CoV-2 has caused person-to-person transmission all over the world. ${ }^{4-8}$

The coronavirus disease 2019 (COVID-19) has already spread rapidly to most parts of China as well as around the world, which has been declared as a pandemic by the World Health Organization (WHO). ${ }^{9}$ COVID-19 is more likely to develop to a critically ill level and has caused higher mortality especially in patients with 
metabolic disorders (diabetes, obesity, hypertension, etc). ${ }^{10-12}$ The clinical spectrum of COVID-19 ranges from mild to critically ill cases. Previous studies have described the general clinical features of patients infected with SARSCoV-2, including epidemiological, clinical, laboratory, radiological characteristics, treatment, and outcomes. ${ }^{1,11,13-16} \mathrm{At}$ present, controlling the morbidity of critically ill cases and reducing mortality still remain a great challenge for COVID19. ${ }^{17}$ However, the clinical information characterizing critically ill patients was insufficient. One study has described the clinical course and outcomes of 52 critically ill patients with confirmed COVID-19 who were admitted to the intensive care unit (ICU) of Wuhan Jin Yin-tan hospital (Wuhan, China). ${ }^{18}$ COVID-19 is becoming increasingly severe in other countries and regions outside China, Therefore, comprehensive analysis of data from different centers is necessary to ultimately establish treatment guidelines and risk score for COVID-19. An updated analysis to investigate critically ill patients confirmed with SARS-CoV-2 infection will be of vital importance to reduce mortality.

Serum osmolarity, which depends on the concentrations of $\mathrm{Na}^{+}, \mathrm{K}^{+}, \mathrm{Cl}^{-}$, glucose and urea, plays an important role in various body fluid balances. ${ }^{19}$ Perturbation of serum osmolarity is associated with clinically adverse outcomes. The association between hyperosmolarity and mortality has been studied in several diseases, such as patients with acute coronary syndrome, ${ }^{20}$ intracranial hemorrhage, ${ }^{21}$ stroke, $^{22}$ acute pulmonary embolism ${ }^{23}$ as well as in critically ill patients, ${ }^{24}$ the results showed that hyperosmolarity is associated with increased mortality. Additionally, as an acute complication of diabetes, hyperosmolarity is strongly associated with poor outcome or mortality in patients with severe hyperglycemic crisis. For COVID-19, whether hyperosmolarity plays a predictive role in mortality in critically ill patients still remains unclear.

In this study, we investigated critically ill patients with confirmed SARS-CoV-2 pneumonia who were admitted to the ICU of Tongji hospital in Wuhan. We aim to describe the epidemiological, clinical, laboratory, treatment, and outcomes, and to explore the risk factors for death in critically ill patients with COVID-19.

\section{Methods}

\section{Study Design and Participants}

The patients or their authorized person in this study were informed about the purpose of the study, that verbal informed consent was approved by the Institutional Ethics Board of Tongji Hospital, Huazhong University of Science and Technology (No. TJ-IRB20200315), and that this study was conducted in accordance with the Declaration of Helsinki. This retrospective, observational study was done at Tongji Hospital in Wuhan (China), which is the designated hospital for treatment for COVID-19. All patients with COVID-19 enrolled in this study were confirmed with SARS-CoV-2 infection by PCR according to World Health Organization interim guidance. $^{25}$ We enrolled patients admitted to ICU in Tongji Hospital from Feb 4, 2020 to Feb 20, 2020. Among them, 146 had appeared outcomes and were included in the final analysis after excluding 14 other patients (13 were still hospitalized and 1 was transferred). Critically ill patients were defined as those admitted to the ICU who required mechanical ventilation or had a fraction of inspired oxygen (FiO2) of at least $60 \%$ or more as previously described. ${ }^{18}$ The clinical outcomes (ie, dead, improved, still hospitalized in ICU) were monitored up to March 11, 2020, the final date of follow-up. The study flow diagram is shown in Figure 1.

\section{Data Collection}

We collected clinical medical records, nursing records, and laboratory findings for all patients with laboratory confirmed COVID-19 with standardized data collection forms. The data were reviewed by a trained team of physicians. We collected data on age, sex, medical history, smoking history, chronic comorbidities (hypertension, chronic cardiac disease, cerebrovascular disease, chronic pulmonary disease, chronic kidney disease, chronic liver disease, cancer, and diabetes), symptoms from onset to hospital admission (fever, the highest temperature, cough, expectoration, dyspnoea, chest pain, diarrhea, nausea, vomiting, poor appetite, myalgia, headache, and fatigue), vital signs at hospital admission (temperature, blood pressure, heart rate, respiratory rate and oxygen saturation), laboratory tests on hospital admission and treatments (antiviral therapy, Chinese patent medicine, antibiotics therapy, corticosteroid, mechanical ventilation and life support).

\section{Definitions}

The laboratory abnormalities were according to the normal value range of the clinical laboratory in Tongji Hospital. Diabetic ketoacidosis, acute kidney injury, rhabdomyolysis, and disseminated intravascular coagulation were defined by clinicians according to the clinical 
223 patients with confirmed SARS-CoV-2 pneumonia

were admitted to icu as of February 29,2020

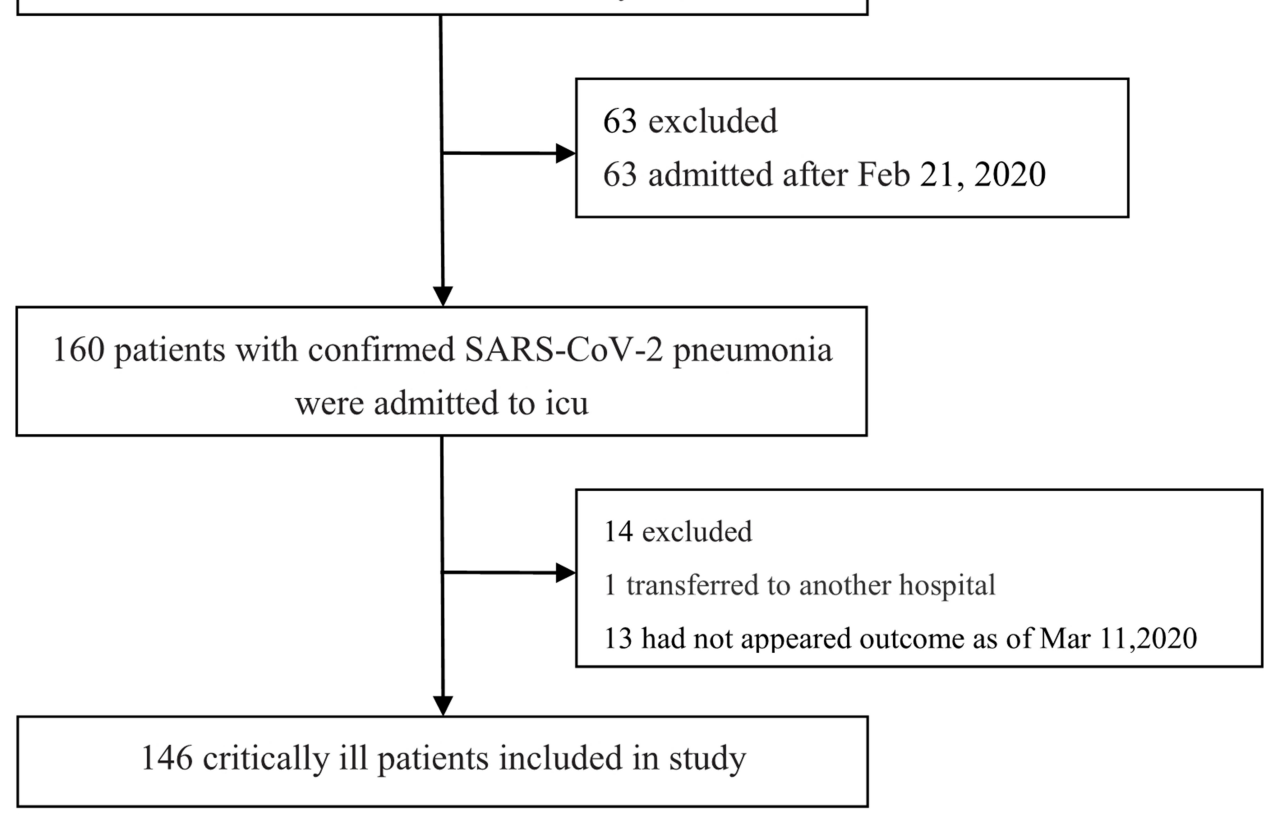

Figure I Study flow diagram.

guideline. ${ }^{26-28}$ Cardiac injury was defined if the serum high sensitivity cardiac troponin I (cTnI) was above 131 $\mathrm{pg} / \mathrm{mL}$. Hepatic dysfunction was defined if alanine transaminase (ALT) was above 3 folds of the upper limit of normal. The effective plasma osmolarity was calculated by ( $\operatorname{sodium}(\mathrm{mmol} / \mathrm{L})+$ potassium $(\mathrm{mmol} / \mathrm{L})) * 2+$ random blood glucose $(\mathrm{mmol} / \mathrm{L})$, the estimated plasma osmolarity above $320 \mathrm{mOsm} / \mathrm{L}$ was defined as hyperosmolarity. The collected laboratory tests were on hospital admission.

\section{Statistical Analysis}

Continuous variables were described as the medians and interquartile ranges (IQR). Categorical variables were expressed as the frequency and its percentages in each group. According to their outcomes, we eliminated the cases that had no apparent outcome yet and grouped the remaining cases into improvement or death to compare their differences. When the data was normally distributed, independent group $t$-tests were used for continuous variables; otherwise, Wilcoxon rank-sum tests were applied. While chi-square tests and Fisher's exact tests were applied to categorical variables as appropriate. To analyze the odds ratios of death versus improvement among ICU cases and the potential risk factors, we fitted a logistic regression model. The candidate risk factors included gender, age, laboratory findings and the development of complications. Firstly, we incorporated a single candidate variable from those candidate risk factors into the univariate models orderly. Then, the statistically significant risk factors in univariate models were included into the final models. All analyses were conducted with SAS software version 9.4. The forest figure was plotted using R software version 3.6.3.

\section{Results}

\section{Demographic and Clinical Characteristics}

The study population included 160 patients with COVID-19 who had been hospitalized in the ICU of Tongji Hospital, and obtained data regarding clinical symptoms and outcomes. Among them, 146 with appeared outcomes were included into the final analysis (27 patients improved and 119 died during hospitalization), 13 were still hospitalized and 1 was transferred. The median durations from onset to hospital admission and ICU admission were 10 days (IQR, 7-15), 14 days (IQR, 10-19) respectively (Supplemental Table 1). The median durations from ICU admission to death or improvement were 7 days (IQR, 3-12) or 9 days (IQR, 7-20) respectively. Compared with the death group, the median time from admission to ICU for the improved group is shorter ( $\mathrm{Z}=$ $-2.7294, \mathrm{P}<0.05$ ), which were 2 days (IQR, $0-5$ ) and 0 day (IQR, 0-3) respectively (Supplemental Table 1). 
Of the 146 patients, the median age was 69 years (IQR, 59-76; range, 22-92 years), and $61.6 \%$ of the patients were men. Patients who died were older than those who improved by a median of 15 years. The demographic and clinical characteristics of the patients are shown in Table 1 and Figure 2. The most common symptoms at onset of illness were fever (127 [88.8\%]), dyspnea (112 [78.3\%]), cough (110 [76.9\%]), fatigue (69 [48.6\%]), and poor appetite (65 [45.8\%]). Less common symptoms were headache, chest pain, diarrhea, nausea, and vomiting (Supplemental Table 2). Dyspnea was more common in patients who died than in the improved group. Among the overall population, hypertension (69 [49.3\%]) was the most common chronic coexisting condition. Acute complications among the 146 patients included poor liver function (57 [40.1\%]), myocardial injury (47 [34.3\%]), hyperuricemia (27 [19.0\%]), and hypernatremia (24 [17.0\%]) (Table 1).
On admission to hospital, temperature, pulse, respiratory rate, and blood pressure did not differ between patients who died and patients with improved. The blood oxygen saturation of the death group was significantly lower than that of the improved group $(\mathrm{t}=3.0052, \mathrm{P}<0.05)$ (Supplemental Table 2). Compared with patients who improved $(n=27)$, patients who died $(n=119)$ had more dyspnea (Supplemental Table 2) and higher random blood glucose (8.32 [6.55 12.38] vs 7.05 [5.49 9.50], $\mathrm{P}=0.043$ ) (Table 2), and were more likely to have underlying comorbidities, like myocardial damage (44 [39.6\%] vs 3 [11.5\%], $\mathrm{P}=0.007$ ) (Table 1). The result also showed the comorbidities, such as hypertension (58 [50.4\%] vs 11 [44.0\%]), chronic pulmonary disease (11 [9.6\%] vs $0[0 \%])$, and cardiovascular disease (25 [21.7\%] vs $4[16.7 \%]$ ) were more common in the death group, although this difference was not statistically significant (Table 1). The death group was more likely to have one of these complications than improved patients.

Table I Baseline Characteristics of I46 Critically III Patients with COVID-19

\begin{tabular}{|c|c|c|c|c|}
\hline & All Patients( $n=146)$ & $\operatorname{Death}(n=1 \mid 9)$ & Improvement(n=27) & $P$ value \\
\hline Age years & $69(59 \sim 76)$ & $70(62 \sim 78)$ & $55(36 \sim 7 I)$ & $<0.001$ \\
\hline \multicolumn{5}{|l|}{ Distribution } \\
\hline$<65$ & $54(37.0)$ & $38(31.9)$ & $16(59.3)$ & 0.008 \\
\hline$\geq 65$ & $92(63.0)$ & $8 I(68.1)$ & II (40.7) & \\
\hline \multicolumn{5}{|l|}{ Sex } \\
\hline Male & $90(61.6)$ & $76(63.9)$ & $14(5 \mid .9)$ & 0.246 \\
\hline Female & $56(38.4)$ & $43(36.1)$ & $13(48.1)$ & \\
\hline Smoking history & $15(11.4)$ & $13(1 \mid .8)$ & $2(9.1)$ & $>0.99$ \\
\hline \multicolumn{5}{|l|}{ Chronic coexisting disorders } \\
\hline Hypertension & $69(49.3)$ & $58(50.4)$ & II (44.0) & 0.560 \\
\hline Cardiovascular disease & $29(20.9)$ & $25(21.7)$ & $4(16.7)$ & 0.578 \\
\hline Cerebrovascular diseases & $9(6.5)$ & $7(6.1)$ & $2(8.3)$ & $>0.99$ \\
\hline Chronic pulmonary disease & II (7.9) & $\mathrm{II}(9.6)$ & $0(0)$ & 0.245 \\
\hline Chronic renal diseases & $5(3.6)$ & $3(2.6)$ & $2(8.3)$ & 0.206 \\
\hline Chronic liver disease & $5(3.6)$ & $5(4.3)$ & $0(0)$ & 0.587 \\
\hline Cancer & $4(3.4)$ & $3(3.1)$ & $\mathrm{I}(4.3)$ & 0.582 \\
\hline Diabetes & $48(33.8)$ & $40(34.2)$ & $8(32.0)$ & 0.834 \\
\hline \multicolumn{5}{|l|}{ Acute coexisting disorders } \\
\hline Hepatic dysfunction & $57(40.1)$ & $49(42.2)$ & $8(30.8)$ & $0.28 \mathrm{I}$ \\
\hline Hypernatremia & $24(17.0)$ & $23(20.0)$ & $\mathrm{I}(3.8)$ & 0.996 \\
\hline Hyperuricemia & $27(19.0)$ & $23(19.8)$ & $4(15.4)$ & 0.806 \\
\hline Myocardial damage & $47(34.3)$ & $44(39.6)$ & $3(11.5)$ & 0.007 \\
\hline Rhabdomyolysis & $\mathrm{I}(0.7)$ & $\mathrm{I}(0.8)$ & $0(0)$ & $>0.99$ \\
\hline Acute kidney injury & $3(2.1)$ & $3(2.5)$ & $0(0)$ & $>0.99$ \\
\hline Disseminated intravascular coagulation & $\mathrm{I}(0.7)$ & $\mathrm{I}(0.8)$ & $0(0)$ & $>0.99$ \\
\hline
\end{tabular}

Notes: Data are presented as $\mathrm{n}(\%)$ or median (interquartile range), unless otherwise stated; ${ }^{\text {a }} \mathrm{P}$ values indicate differences between death and improvement; $\mathrm{P}<0.05$ was considered statistically significant.

Abbreviations: COVID-19, the coronavirus disease 2019; bpm, beats per minute. 
A

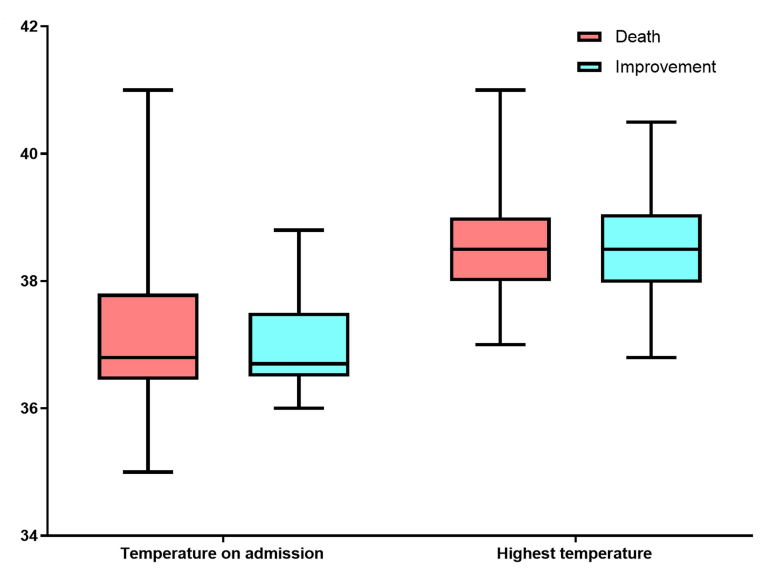

B

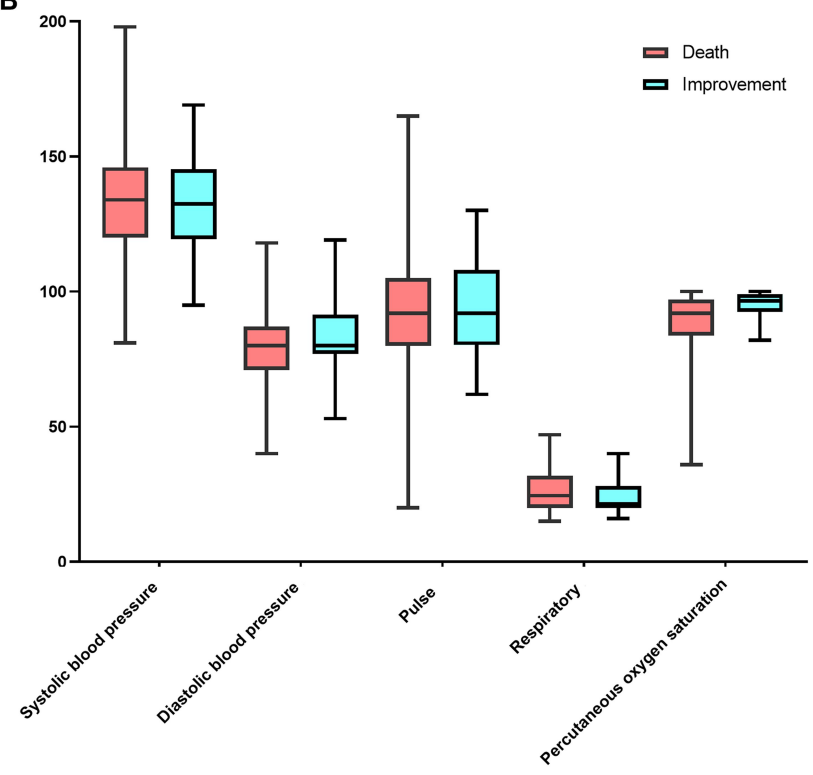

C

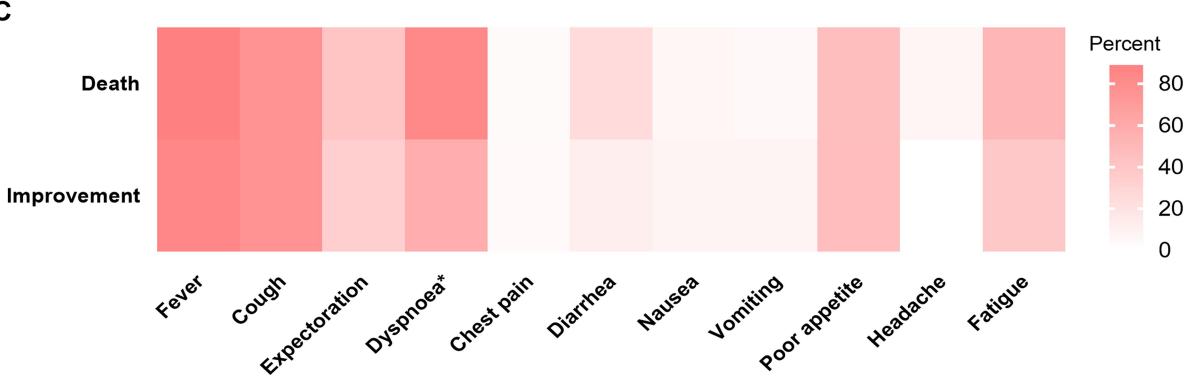

Figure 2 Clinical symptoms and signs of 146 critically ill patients with COVID-19. (A and B) The average (with standard deviation) of clinical signs in the death and the improvement. (C) Percentage of each clinical symptom in the death and the improvement. *Represents $\mathrm{P}<0.05$.

\section{Factors Associated with Plasma Osmolarity}

We were especially concerned with the factors contributing to plasma osmolarity shown in Table 2. The reference range of laboratory findings were listed in Supplemental Table 5. Compared with patients who improved $(n=27)$, patients who died $(n=119)$ had higher sodium, blood glucose, and effective plasma osmolarity. In the subgroup of diabetes, the sodium and effective plasma osmolarity were higher in the death group, and the difference of effective plasma osmolarity were more marked. But there was no difference of blood glucose between deaths and survivors in patients with diabetes (Table 2, Figure 3 and Supplemental Table 3). Besides, there were 7 patients with diabetes with hyperosmolar status and all of them died. There was no difference of diabetes ketoacidosis in the death group and improved group (Table 2).

\section{Laboratory Parameters and Treatment}

The laboratory tests of the patients on admission are shown in Table 3. There were numerous differences in laboratory tests between the improvement group and the death group. Patients from the death group had more significant laboratory abnormalities, including higher levels of lactic dehydrogenase, total protein, d-dimer, C-reactive protein (CRP), serum ferritin, high sensitivity cTnI, interleukin-2 receptor (IL-2R), interleukin-6 (IL-6), interleukin-8 (IL-8), interleukin-10 (IL-10) and brain natriuretic peptide level (BNP), as well as lower lymphocyte count, platelet count, estimated glomerular filtration rate (eGFR), actual bicarbonate (AB) and total cholesterol level. 
Table 2 Factors Associated with Plasma Osmolarity of I46 Critically III Patients with COVID-I9

\begin{tabular}{|c|c|c|c|c|}
\hline & All & Death & Improvement & $P$ value $^{\mathrm{a}}$ \\
\hline All patients, counts & 146 & 119 & 27 & \\
\hline Hyperosmolar status & $7(5.1)$ & $7(6.3)$ & $0(0.0)$ & 0.350 \\
\hline Diabetes ketoacidosis & $2(1.5)$ & $\mathrm{I}(0.9)$ & $\mathrm{I}(4.0)$ & 0.333 \\
\hline Potassium $\mathrm{mmol} \cdot \mathrm{L}^{-1}$ & $4.39(3.88 \sim 4.82)$ & $4.38(3.78 \sim 4.83)$ & $4.44(4.17 \sim 4.82)$ & 0.458 \\
\hline Sodium $\mathrm{mmol} \cdot \mathrm{L}^{-1}$ & $139.20(|36.20 \sim| 43.20)$ & $139.70(|36.40 \sim| 44.00)$ & $138.25(|35.30 \sim| 39.50)$ & 0.034 \\
\hline Random blood glucose $\mathrm{mmol}^{-1}$ & $7.94(6.31 \sim 11.73)$ & $8.32(6.55 \sim 12.38)$ & $7.05(5.49 \sim 9.50)$ & 0.043 \\
\hline Plasma osmolarity mOsm/L & $296.47(290.3 \mathrm{I} \sim 305.26)$ & $298.32(290.50 \sim 308.37)$ & $293.23(289.74 \sim 296.82)$ & 0.033 \\
\hline Patients with diabetes, counts & 48 & 40 & 8 & \\
\hline Hyperosmolar status & $7(14.9)$ & $7(17.9)$ & $0(0.0)$ & 0.329 \\
\hline Diabetes ketoacidosis & $2(4.3)$ & $\mathrm{I}(2.6)$ & $\mathrm{I}(12.5)$ & 0.315 \\
\hline Potassium $\mathrm{mmol} \cdot \mathrm{L}^{-1}$ & $4.43(3.91 \sim 4.89)$ & $4.48(3.91 \sim 4.89)$ & $4.38(3.86 \sim 5.01)$ & 0.729 \\
\hline Sodium $\mathrm{mmol} \cdot \mathrm{L}^{-1}$ & $139.60(136.05 \sim 145.95)$ & $142.10(137.55 \sim 149.20)$ & $136.85(\mid 34.50 \sim 139.05)$ & 0.046 \\
\hline Random blood glucose $\mathrm{mmol}^{-1}$ & $14.67(\mid I .3 \mathrm{I} \sim 18.17)$ & $14.83(\mid 1.77 \sim 18.53)$ & $12.46(10.13 \sim 16.99)$ & 0.313 \\
\hline Plasma osmolarity mOsm/L & $303.86(296.00 \sim 319.15)$ & $308.97(297.1 I \sim 324.33)$ & $296.20(292.86 \sim 296.67)$ & 0.013 \\
\hline
\end{tabular}

Notes: Data are presented as $\mathrm{n}(\%)$ or median (interquartile range), unless otherwise stated; ${ }^{\mathrm{P}} \mathrm{P}$ values indicate differences between death and improvement, $\mathrm{P}<0.05$ was considered statistically significant.

Abbreviation: COVID-19, the coronavirus disease 2019.

The treatment of the 146 critically ill patients is shown in Table 4. A majority of the patients $(97.2 \%)$ received antibiotic therapy, $82.6 \%$ received antiviral therapy, and $87.1 \%$ received corticosteroid therapy; non-surviving patients received higher doses of corticosteroid. Most patients $(67.6 \%)$ received endotracheal intubation, and higher percentages of non-surviving patients received this therapy. Patients in the improvement group were more likely to receive nasal catheter oxygen inhalation than those in the death group. Of all critically ill patients with COVID-19, few received high-flow oxygen $(2.1 \%)$ and

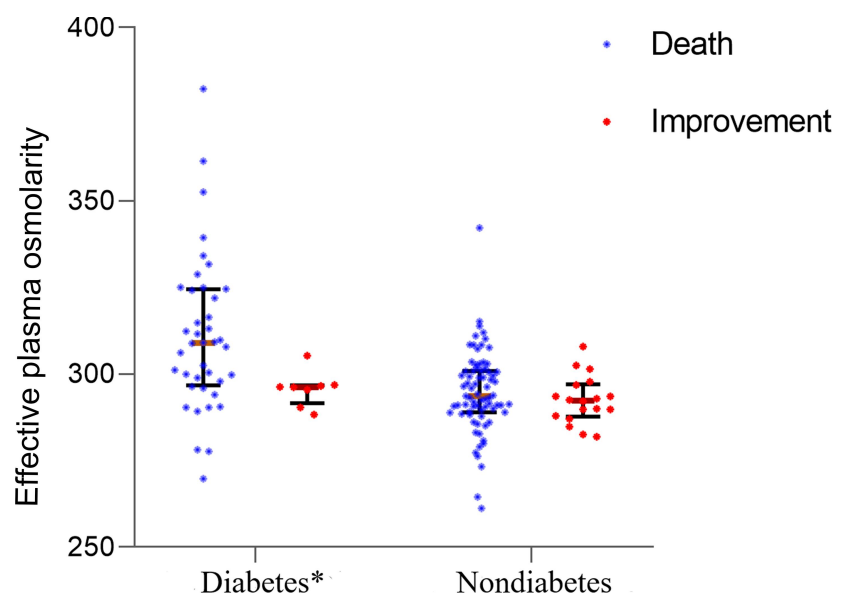

Figure 3 The plasma osmolarity of 146 critically ill patients with COVID-19. The median (interquartile range) of plasma osmolarity in patients with or without diabetes. *Represents $\mathrm{P}<0.05$. extracorporeal membrane oxygenation (2.1\%). More patients in the dead group received replacement therapy than in the improved group (26 [21.8\%] vs 2 [7.7\%]).

\section{Risk Factors for Mortality in Patient with COVID-19}

In univariable analysis, the odds of in-ICU death was higher in patients with dyspnea (Supplemental Table 4). Age, dyspnea, lymphopenia, reduced eGFR and oxygen saturation, increased CRP, prothrombin time (PT), d-dimer, IL-6 and serum ferritin, were also associated with death.

Based upon the above results, we included 114 patients with complete data for all variables (25 improved and 89 died) in the multivariable logistic regression model. We found that older age, higher CRP, IL- 6 , and a d-dimer greater than $1 \mu \mathrm{g} / \mathrm{mL}$ at admission were associated with increased odds of death (Figure 4).

\section{Correlation Among Osmolarity and the Inflammatory Markers}

In addition, we analyzed the correlation relationship between osmolarity and inflammatory markers (Supplemental Table 6). The results showed that the lymphocyte count $(\mathrm{r}=-0.1831$, $\mathrm{P}=0.0309)$, lactic dehydrogenase $(\mathrm{r}=0.3439, \mathrm{P}<0.0001)$, total bilirubin $(\mathrm{r}=0.4017, \mathrm{P}<0.0001)$, d-dimer $(\mathrm{r}=0.2226, \mathrm{P}=$ $0.0089)$, interleukin-6 $(r=0.3398, P=0.0002)$, interleukin- 8 ( $r$ 
Table 3 Laboratory Findings of 146 Critically III Patients with COVID-19

\begin{tabular}{|c|c|c|c|c|}
\hline & All Patients $(n=146)$ & $\operatorname{Death}(n=\mid 19)$ & Improvement(n=27) & $P$ value ${ }^{a}$ \\
\hline White-cell count $\times 10^{9} \cdot \mathrm{L}^{-1}$ & $8.96(6.17 \sim 13.08)$ & $9.15(6.15 \sim 13.35)$ & $7.89(6.17 \sim 10.66)$ & 0.245 \\
\hline Neutrophil count $\times 10^{9} \mathrm{~L}^{-1}$ & $7.85(4.90 \sim 11.60)$ & $8.10(5.38 \sim 12.02)$ & $5.8 \mathrm{I}(4.6 \mathrm{I} \sim 9.69)$ & 0.107 \\
\hline Lymphocyte count $\times 10^{9} \mathrm{~L}^{-1}$ & $0.58(0.43 \sim 0.86)$ & $0.56(0.43 \sim 0.80)$ & $0.79(0.49 \sim 1.12)$ & 0.023 \\
\hline Monocyte count $\times 10^{9} \cdot \mathrm{L}^{-1}$ & $0.39(0.25 \sim 0.60)$ & $0.37(0.23 \sim 0.55)$ & $0.47(0.28 \sim 0.87)$ & 0.092 \\
\hline Eosinophil count $\times 10^{9} \cdot \mathrm{L}^{-1}$ & $0.00(0.00 \sim 0.02)$ & $0.00(0.00 \sim 0.0 \mathrm{I})$ & $0.03(0.00 \sim 0.09)$ & $<0.001$ \\
\hline Erythrocyte count $\times 10^{12} \cdot \mathrm{L}^{-1}$ & $4.12(3.7 I \sim 4.54)$ & $4.16(3.83 \sim 4.55)$ & $3.80(3.56 \sim 4.45)$ & 0.105 \\
\hline Haemoglobin level $g \cdot \mathrm{L}^{-1}$ & $\mid 29.0(|| 6.0 \sim|4| .0)$ & $131.5(|17.0 \sim| 42.5)$ & $120.5(108.0 \sim 138.0)$ & 0.062 \\
\hline Platelet count $\times 10^{9} \cdot \mathrm{L}^{-1}$ & $161.0(118.0 \sim 234.0)$ & $151.0(108.0 \sim 223.0)$ & $202.0(152.0 \sim 317.0)$ & $<0.001$ \\
\hline Alanine transaminase $\mathrm{U} \cdot \mathrm{L}^{-\mathrm{lb}}$ & $29.5(19.0 \sim 46.0)$ & $29.0(19.0 \sim 43.5)$ & $34.5(20.0 \sim 65.0)$ & 0.288 \\
\hline Aspartate aminotransferase $\mathrm{U} \cdot \mathrm{L}^{-\mathrm{lb}}$ & $40.5(26.0 \sim 63.0)$ & $43.5(29.5 \sim 63.5)$ & $32.5(22.0 \sim 47.0)$ & 0.101 \\
\hline Lactic dehydrogenase $U \cdot \mathrm{L}^{-\mathrm{lb}}$ & $506.5(376.0 \sim 695.0)$ & $540.0(422.5 \sim 742.0)$ & $361.0(282.0 \sim 485.0)$ & 0.009 \\
\hline Creatine kinase $\mathrm{U} \cdot \mathrm{L}^{-1 \mathrm{~b}}$ & $133.5(70.0 \sim 354.0)$ & $133.5(73.0 \sim 356.0)$ & $127.0(36.5 \sim 239.0)$ & 0.075 \\
\hline Total bilirubin $\mu \mathrm{mol} \mathrm{L}^{-1}$ & $13.25(8.50 \sim 19.20)$ & $13.90(9.80 \sim 20.60)$ & $8.85(7.20 \sim 14.40)$ & 0.007 \\
\hline Albumin $g \cdot \mathrm{L}^{-1}$ & $31.00(27.50 \sim 33.80)$ & $30.80(27.35 \sim 33.40)$ & $31.35(27.80 \sim 35.60)$ & 0.057 \\
\hline eGFR $\mathrm{mL} \cdot \min ^{-1}$ & $76.01(52.47 \sim 94.09)$ & $71.98(48.74 \sim 90.63)$ & $94.95(73.74 \sim 116.95)$ & $<0.001$ \\
\hline Actual bicarbonate $\mathrm{mmol} \cdot \mathrm{L}^{-1}$ & $21.50(18.80 \sim 24.10)$ & $20.90(18.60 \sim 23.90)$ & $23.25(21.90 \sim 25.25)$ & 0.007 \\
\hline Uric Acid $\mu \mathrm{mol} \cdot \mathrm{L}^{-1}$ & $259.55(181.00 \sim 373.00)$ & $261.55(184.00 \sim 378.50)$ & $219.00(165.00 \sim 364.00)$ & 0.367 \\
\hline Total Cholesterol $\mathrm{mmol} \mathrm{L}^{-1}$ & $3.35(2.90 \sim 3.97)$ & $3.33(2.75 \sim 3.87)$ & $3.67(3.16 \sim 4.49)$ & 0.006 \\
\hline Triglyceride $\mathrm{mmol} \cdot \mathrm{L}^{-1}$ & $1.56(1.20 \sim 2.23)$ & $1.57(1.22 \sim 2.23)$ & $1.48(1.18 \sim 2.34)$ & 0.681 \\
\hline Glycosylated hemoglobin $\mathrm{mmol} \cdot \mathrm{L}^{-1}$ & $6.45(6.15 \sim 6.80)$ & $6.50(6.20 \sim 6.90)$ & $6.40(6.00 \sim 6.60)$ & 0.347 \\
\hline Calcium $\mathrm{mmol} \cdot \mathrm{L}^{-1}$ & $2.08(2.00 \sim 2.19)$ & $2.07(1.98 \sim 2.15)$ & $2.17(2.05 \sim 2.24)$ & 0.024 \\
\hline Prothrombin time s & $15.4(14.4 \sim 17.3)$ & $15.6(14.6 \sim 17.7)$ & $14.5(|3.8 \sim| 5.5)$ & 0.002 \\
\hline D-dimer $m g \cdot \mathrm{L}^{-1}$ & $6.89(1.74 \sim 21.00)$ & $10.46(2.12 \sim 21.00)$ & $2.26(I .02 \sim 6.7 I)$ & 0.002 \\
\hline C-reactive protein $\mathrm{mg} \cdot \mathrm{L}^{-1}$ & $97.20(47.30 \sim 142.10)$ & $107.30(60.70 \sim 150.50)$ & $44.65(19.00 \sim 91.90)$ & $<0.001$ \\
\hline Erythrocyte sedimentation rate $\mathrm{mm} \mathrm{H}^{-1}$ & $36(20 \sim 62)$ & $35(19 \sim 59)$ & $53(28 \sim 72)$ & 0.175 \\
\hline Procalcitonin $\mathrm{ng} \cdot \mathrm{mL}^{-1}$ & $0.20(0.10 \sim 0.66)$ & $0.20(0.11 \sim 0.67)$ & $0.14(0.06 \sim 0.26)$ & 0.034 \\
\hline Serum ferritin $\mu \mathrm{g} \cdot \mathrm{L}^{-1}$ & I294.2(856.5 2290.4) & |352. I(969.9 24|2.4) & $825.3(643.4 \sim 1555.9)$ & 0.007 \\
\hline Brain natriuretic peptide $\mathrm{pg} \mathrm{mL}^{-1}$ & $804.5(226.0 \sim 2545.0)$ & $945.0(362.0 \sim 2636.0)$ & $155.5(75.0 \sim 852.0)$ & $<0.001$ \\
\hline Cardiac troponin I pg $\mathrm{mL}^{-1}$ & $31.15(9.45 \sim 271.15)$ & $48.70(|2.10 \sim 47| .20)$ & $6.60(2.60 \sim 19.50)$ & $<0.001$ \\
\hline Interleukin-I $\beta \mathrm{pg} \cdot \mathrm{mL}^{-1}$ & $5.00(5.00 \sim 5.00)$ & $5.00(5.00 \sim 5.00)$ & $5.00(5.00 \sim 5.00)$ & 0.258 \\
\hline Interleukin-2R $\cup \mathrm{mL}^{-1}$ & $1092.00(772.00 \sim 1565.00)$ & $1170.00(884.00 \sim 1583.00)$ & $931.00(581.00 \sim 1111.00)$ & 0.025 \\
\hline Interleukin- $6 \mathrm{pg} \cdot \mathrm{mL}^{-1}$ & $51.39(22.28 \sim 137.35)$ & $68.00(29.42 \sim 164.40)$ & $22.45(7.60 \sim 31.76)$ & $<0.001$ \\
\hline Interleukin- $8 \mathrm{pg} \cdot \mathrm{mL}^{-1}$ & $26.10(15.50 \sim 56.00)$ & $32.25(17.55 \sim 69.50)$ & $17.80(10.50 \sim 23.40)$ & $<0.001$ \\
\hline Interleukin- $10 \mathrm{pg} \cdot \mathrm{mL}^{-1}$ & $8.90(5.40 \sim 14.90)$ & $10.10(5.70 \sim 15.60)$ & $6.10(5.00 \sim 8.90)$ & 0.027 \\
\hline Tumor Necrosis Factor- $\alpha \mathrm{pg} \cdot \mathrm{mL}^{-1}$ & $10.70(7.70 \sim 17.50)$ & $\mathrm{II} .30(8.00 \sim 18.30)$ & $9.80(6.80 \sim 14.60)$ & 0.130 \\
\hline
\end{tabular}

Notes: Data are presented as median (interquartile range), unless otherwise stated; Reference range for above laboratory findings were provided in supplementary materials (Supplemental Table 5); ${ }^{\text {a }} \mathrm{P}$ values indicate differences between death and improvement, $\mathrm{P}<0.05$ was considered statistically significant; ${ }^{\text {bS }}$ conversion factors, to convert alanine transferase to $\mu \mathrm{kat} / \mathrm{L}$, multiply by 0.0167 ; aspartate aminotransferase to $\mu \mathrm{kat} / \mathrm{L}$, multiply by 0.0167 ; creatine kinase to $\mu \mathrm{kat} / \mathrm{L}$, multiply by 0.0167 ; and lactate dehydrogenase to $\mu \mathrm{kat} / \mathrm{L}$, multiply by 0.0167 .

Abbreviation: COVID-19, the coronavirus disease 2019.

$=0.2450, \mathrm{P}=0.008)$, and tumor necrosis factor- $\alpha(\mathrm{r}=0.4065$, $\mathrm{P}=<0.0001)$ were significantly correlated with osmolarity.

\section{Discussion}

This retrospective study reported clinical features of 146 critically ill patients (with 27 who improved and 119 who died) who were confirmed as having the SARS-CoV-2 infection. Importantly, plasma hyperosmolarity may contribute to the death rates of critically ill patients with COVID $=19$. Besides, older age, higher CRP, IL-6, and a d-dimer greater than $1 \mu \mathrm{g} / \mathrm{mL}$ at admission were associated with higher odds of in-ICU death.

Importantly, the random blood glucose was higher in the dead group than the improved group. Zhou et al reported that odds of in-hospital death was higher in patients with diabetes $^{29}$ and the blood glucose needed better management in patients with COVID-19. ${ }^{30}$ The random blood glucose, serum sodium and effective plasma osmolarity were higher in deceased patients than in improved patients, which suggestiions that plasma hyperosmolarity may be associated 
with higher mortality. Additionally, the sodium levels were not significant in both univariate and multivariate analysis. A consistent association between hyponatremia and increased mortality has been shown in different hospitalized patients. $^{31-33}$ The osmolarity mainly depends on $\mathrm{Na}^{+}, \mathrm{K}^{+}$, $\mathrm{Cl}^{-}$, glucose and urea. The results in this study indicate that in critically ill patients with COVID-19, blood sodium may not be the main cause in the increased osmolarity. We may need a comprehensive management for all components of osmolarity to improve the outcome of COVID-19. The hyperosmolar status in patients with diabetes did not show a significant difference between the dead and improved group. Specifically, there were 7 patients with diabetes with hyperosmolar hyperglycemia syndrome and all of them were deceased. Meanwhile, there were 2 patients with diabetic ketoacidosis, of which 1 died and another was improved. The results suggest that hyperosmolar status in diabetes but not diabetic ketoacidosis seems to be associated with a higher risk of death in critically ill patients with COVID-19 despite the hyperosmolar status failing to reach a significant statistical difference, which may be due to the limited sample size in this study. In the subgroup of patients with diabetes, the estimated effective plasma osmolarity was also higher in the dead group than in the improved group. As the poor management of blood glucose would aggravate the hyperosmolar status in patients with diabetes, thus increasing the risk for death. It is known that serum osmolarity plays an important role in body fluid balances, while perturbation of serum osmolarity is strongly associated with internal environment disorder, such as dehydration and hypernatremia which may lead to a poor clinical outcome. ${ }^{19}$ It is reported that hyperosmolarity is associated with increased mortality in various diseases. $^{20-24,34}$ First, hyperosmolarity is always accompanied by the increase of its main components, such as hyperglycemia, hypernatremia or hyperkalemia, which have been reported as risk factors for cardiac mortality. ${ }^{35,36}$ Second, hyperosmolarity could cause the redistribution of body fluids, such as transport of fluids from interstitial space to the effective circulation, thus increasing the preload of cardiac and leading to poor outcomes, such as heart failure and malignant arrhythmia. ${ }^{24}$ In this study, we found no significant difference of hyperosmolarity in the mortality of COVID-19 patients after multivariate analysis. This may be because of the limited sample size or the heterogeneity between patients with COVID-19 and patients with other diseases. Further studies are needed to explore the importance of hyperosmolarity in COVID-19 related mortality. These results suggest the importance of early identification and treatment of plasma hyperosmolarity in critically ill patients with COVID-19, especially in patients with diabetes.

Until now, no specific treatment has been identified to treat SARS-CoV-2. Currently, the dominant therapies for COVID-19 are antivirus, Chinese patent medicine, antibiotics, corticosteroids and other non-drug supportive treatments. About $82 \%$ patients in this study received antiviral therapy, $43 \%$ received Chinese patent medicine,

Table 4 Treatment of 146 Critically III Patients with COVID-19

\begin{tabular}{|c|c|c|c|c|}
\hline & All Patients $(n=146)$ & $\operatorname{Death}(n=119)$ & Improvement(n=27) & $P$ value ${ }^{\#}$ \\
\hline \multicolumn{5}{|l|}{ Drug therapy } \\
\hline Antiviral therapy & $114(82.6)$ & $95(83.3)$ & $19(79.2)$ & 0.847 \\
\hline Chinese patent medicine & $54(43.9)$ & $43(42.6)$ & $\mathrm{II}(50.0)$ & 0.525 \\
\hline Antibiotics therapy & I38(97.2) & $114(97.4)$ & $24(96.0)$ & 0.543 \\
\hline Corticosteroid & $122(87.1)$ & $104(89.7)$ & $18(75.0)$ & 0.106 \\
\hline Corticosteroid dose Median (IQR) mg & $40(40 \sim 80)$ & $40(40 \sim 80)$ & $40(0 \sim 80)$ & 0.042 \\
\hline$<40$ & $80(57.1)$ & $63(54.8)$ & $17(68.0)$ & 0.087 \\
\hline $40-80$ & $46(32.9)$ & $38(33)$ & $8(32.0)$ & \\
\hline$>80$ & $14(10)$ & $14(\mid 2.2)$ & $0(0)$ & \\
\hline \multicolumn{5}{|l|}{ Non-drug Therapy } \\
\hline Nasal catheter oxygen inhalation & $17(\mid 1.7)$ & $3(2.5)$ & $14(53.8)$ & $<0.001$ \\
\hline High-flow oxygen & $3(2.1)$ & $0(0)$ & $3(11.5)$ & 0.005 \\
\hline BiPAP & $27(18.6)$ & $25(21)$ & $2(7.7)$ & 0.193 \\
\hline Endotracheal intubation & $98(67.6)$ & $91(76.5)$ & $7(26.9)$ & $<0.001$ \\
\hline Extracorporeal membrane oxygenation & $3(2.1)$ & $3(2.5)$ & $0(0)$ & $>0.99$ \\
\hline Replacement therapy & $28(19.3)$ & $26(21.8)$ & $2(7.7)$ & 0.098 \\
\hline
\end{tabular}

Notes: Data are presented as $\mathrm{n}(\%)$, unless otherwise stated; ${ }^{\#} \mathrm{P}$ values indicate differences between death and improvement, $\mathrm{P}<0.05$ was considered statistically significant. Abbreviations: COVID-19, the coronavirus disease 2019; IQR, interquartile range. 


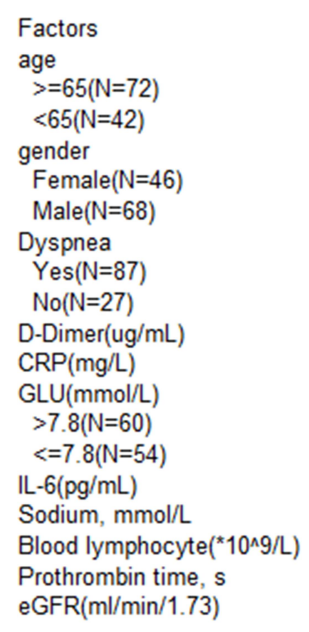

Factors

$>=65(\mathrm{~N}=72)$

$<65(\mathrm{~N}=42)$

Female $(\mathrm{N}=46)$

Male $(\mathrm{N}=68)$

$\mathrm{No}(\mathrm{N}=27)$

D-Dimer(ug/mL)

$\mathrm{CRP}(\mathrm{mg} / \mathrm{L})$

$<=7.8(\mathrm{~N}=54)$

$-6(\mathrm{pg} / \mathrm{mL})$

Blood lymphocyte $\left({ }^{*} 10^{\wedge} 9 / L\right)$

eGFR $(\mathrm{ml} / \mathrm{min} / 1.73$ )

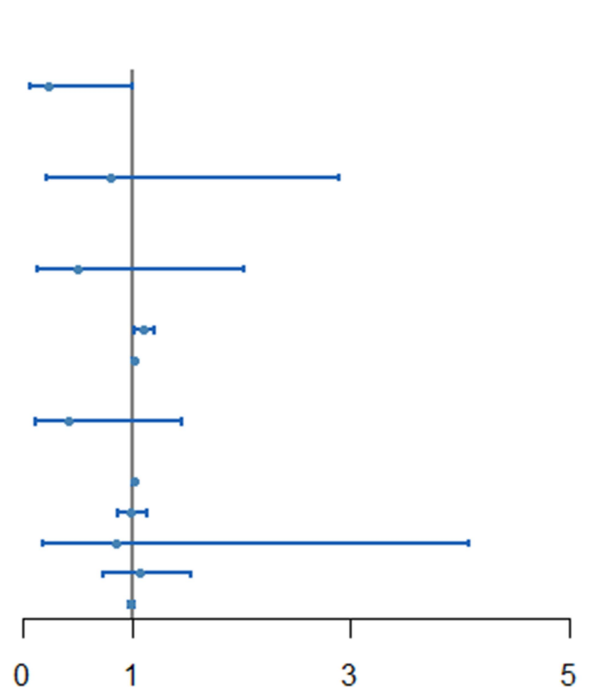

$\begin{array}{cc}P & \text { OR }(95 \% \mathrm{Cl}) \\ 0.049 & 0.23(0.05-0.99) \\ & \\ 0.716 & 0.79(0.21-2.89) \\ & \\ 0.322 & 0.49(0.12-2.01) \\ & \\ 0.032 & 1.1(1.01-1.20) \\ 0.024 & 1.01(1.00-1.03) \\ & \\ 0.166 & 0.41(0.11-1.45) \\ & \\ 0.032 & 1.01(1.00-1.03) \\ 0.915 & 0.99(0.86-1.14) \\ 0.835 & 0.85(0.18-4.09) \\ 0.763 & 1.06(0.73-1.54) \\ 0.523 & 0.99(0.97-1.02)\end{array}$

Figure 4 The risk factors for death in critically ill patients with COVID-19. Shown are the stratification by age, gender, dyspnea, random blood glucose (GLU), and interleukin-6 (IL-6), serum sodium, blood lymphocyte, percutaneous oxygen saturation (spo2), estimated glomerular filtration rate (eGFR), d-Dimer, C-reactive protein (CRP).

and $97 \%$ received antibiotics therapy. At present, no antiviral agents were found to provide a benefit for the outcome of COVID-19. For critically ill patients with a virus infection, corticosteroids were often used to reduce inflammatory-induced lung injury. However, cumulative evidences suggest that corticosteroids did not have effect on mortality in patients with SARS-CoV and MERS-CoV, but rather delayed the virus clearance. ${ }^{37,38}$ In this study, about $87 \%$ of critically ill patients with COVID-19 received corticosteroid therapy. The number of patients who received corticosteroid was more in the death group than for those who improved. Despite the fact that $1-2 \mathrm{mg} / \mathrm{kg} / \mathrm{d}$ corticosteroid was recommended for critically ill patients in the 7th guideline for COVID-19 in China, no improved patients were observed in those received more than $80 \mathrm{mg} /$ d methylprednisolone sodiumsuccinate in this study, suggesting the dose of corticosteroid of more than $80 \mathrm{mg} / \mathrm{d}$ may exhibit no improved effect on outcome of COVID-19. Corticosteroid therapy is often accompanied by elevated blood glucose and sodium storage, which may exacerbate the plasma osmolarity. Therefore, physicians should be more cautious of the corticosteroid therapy in patients with diabetes. Inconsistently, a recent study by researchers from the RECOVERY clinical trial found that dexamethasone reduced 28-day mortality. The benefit was greatest in patients who received either invasive mechanical ventilation or oxygen alone but not among those receiving no respiratory support. $^{39}$ Meanwhile, another research observed that intravenous dexamethasone resulted in a significant increase in the number of ventilator-free days among patients with COVID-19 and moderate or severe ARDS, but there was no significant difference in all-cause mortality at 28 days. ${ }^{40}$ The difference may be explained by several factors. First, Wuhan received an early attack by COVID-19, the health care system was confronted with a heavy burden at the early stage of the epidemic. So, the patients enrolled in this study at the initial stage may be more severe than other studies, which exhibited higher mortality than these two studies. Therefore, the benefit of corticosteroids on mortality was not observed in this study. Second, the limited numbers in this study and the heterogeneity between different ethnic groups may be the reason for different results. Third, methylprednisolone sodium succinate was used in this study instead of dexamethasone in other studies. The different physicochemical property of diverse corticosteroids may contribute to the discrepancy in different studies.

Mechanical ventilation and life support are the main supportive treatments for critically ill patients. In this study, about $67 \%$ patients received endotracheal intubation, higher percentages of non-surviving patients received this therapy. Some first-line physicians suggest that the endotracheal intubation should be applied before the patients progressed to critically ill to achieve better prognosis. In this cohort, 8 patients received ECMO, of which 3 died and 5 were still hospitalized, which suggests that ECMO might prolong the survival time for critically ill 
patients, and the effect of ECMO on the outcome of COVID-19 still needs further investigation.

SARS-CoV-2 can be transmitted directly to humans and has already spread around the world. ${ }^{5,7}$ The two highly pathogenic viruses, SARS-CoV and MERS$\mathrm{CoV}$, have caused severe respiratory syndrome in humans, with a mortality of $10 \%$ for SARS-CoV and $37 \%$ for MERS-CoV. ${ }^{41-43}$ At data cutoff for this study, mortality of the 146 included critically ill patients infected by SARS-CoV-2 was $74 \%$, which was higher than a previous study in critically ill patients. ${ }^{18}$ This may be because the cases of previous study were from the early treatment stage of COVID-19, and the cases of current study are from the outbreak stage in which the situation of patients was aggravated.

Our results showed that older age $(\geq 65)$ was associated with death in ICU patients with COVID-19 and was the greatest risk factor for death, consistent with previous studies. ${ }^{18,29}$ The number of men was more than women in patients admitted to ICU in our study. No association between smoking and death outcome was observed in this study. The time from hospital admission to ICU admission was longer in patients who died than those who improved, suggesting timely treatment into ICU may improve the outcome of COVID-19.

The clinical features of COVID-19 were similar with patients presented with SARS-CoV and MERS-CoV infection, which was similar with previous studies. ${ }^{1,11,13,14,18,29,44,45}$ Dyspnoea was more common in patients who died in this study, which was the only symptom associated with death. The oxygen saturation was lower in the dead group. This may be because dyspnoea and worse oxygen saturation are usually associated with severe clinical status and delayed treatment. The result suggests the onset of dysponea and hypoxia may predict poor prognosis, timely hospitalization and treatment may improve the outcome.

In terms of laboratory tests, lymphocytopenia was observed in about $84 \%$ of critically ill patients in this cohort. Besides, the absolute value of lymphocyte reduced more dramatically in patients who did not survive. The results suggest that SARS-CoV-2 might mainly target lymphocytes, thus damaging the immune system for virus replication. Additionally, lymphocytopenia are also common in critically ill patients with SARS-CoV and MERS-CoV infection. ${ }^{46,47}$ Based on previous studies, ${ }^{13,18,45}$ the lymphocytopenia was associated with the poor outcome. The eosinophil and platelet counts were also reduced in patients who died than those who improved in the current study. It is reported that eosinopenia was observed in most patients infected with SARS-CoV-2, which correlates positively with lymphocyte counts in severe patients. ${ }^{48}$ Platelets are associated with the coagulation function and may be associated with the poor outcome of a SARS-CoV-2 infection, similar to previous studies. ${ }^{13,14}$

The prolonged PT, elevated bilirubin and decreased albumin revealed the dysfunction of liver in critically ill patients, which indicates that hepatic dysfunction may be associated with a high risk for in-ICU death of COVID-19. The d-dimer being greater than $1 \mu \mathrm{g} / \mathrm{mL}$ at admission was a risk factor for the fatal outcome of critically ill patients with COVID-19, consistent with a previous study. ${ }^{29}$ In this study, BNP and high sensitivity cTnI were higher in patients who were dead than those who improved, suggesting that acute heart damage may contribute to the poor outcome of patients in ICU with COVID-19.

Virus infection commonly induces cytokine storm to generate immune responses. Patients with cytokine storm progressed rapidly to acute respiratory distress syndrome or septic shock. Therefore, early identification and management of cytokine storm is crucial for critically ill patients with virus infection. SARS-CoV and MERS-CoV infection were reported to induce increased serum proinflammatory cytokines. ${ }^{49,50}$ In patients with SARS-CoV-2 infection, the proinflammatory cytokine were increased in recent studies. ${ }^{1,51}$ Similarly, the inflammatory factors and cytokines in serum were higher in patients who died than those who improved in this study, which suggests the inflammatory factors and cytokine storm are associated with disease severity and poor outcome. Among all these cytokines, IL-6 and CRP are risk factors for ICU-death.

This study has several limitations. First, information of some cases in this cohort was incomplete, which may affect the results. This is because some patients were too ill to answer questions properly, and it was hard to obtain accurate disease history from these patients. Second, only 146 critically ill patients were included in this study. The limited sample size, especially in the improved group, may make it difficult to assess the risk factors for death in critically ill patients. The non-significant $p$ values should not necessarily rule out a difference between dead and improved patients. Third, at the time of manuscript submission, there are 14 patients still hospitalized and the outcomes are unknown. Additionally, more complete, rigorous, larger clinical studies are needed to uncover the predictive risk factors for death in critically ill patients with COVID-19. 


\section{Conclusion}

In conclusion, hyperosmolarity needs more attention and may contribute to mortality in critically ill patients with COVID-19, especially in those with diabetes. Older age, inflammatory response (higher C-reactive protein and interleukin-6), and thrombosis (d-dimer greater than $1 \mu \mathrm{g} / \mathrm{mL}$ ) at admission may be risk factors for death of critically ill patients with COVID-19.

\section{Abbreviations}

SARS-CoV-2, severe acute respiratory syndrome coronavirus 2; SARS-CoV, severe acute respiratory syndrome coronavirus; MERS-CoV, middle east respiratory syndrome coronavirus; COVID-19, the coronavirus disease 2019; $\mathrm{FiO} 2$, fraction of inspired oxygen; IQR, interquartile range; ICU, the intensive care unit; ALT, alanine transaminase; CK, creatine kinase; CRP, C-reactive protein; cTnI, cardiac troponin I; PT, prothrombin time; IL-2R, interleukin-2 receptor; IL-6, interleukin-6; IL-8, interleukin-8; IL-10, interleukin10; eGFR, estimated glomerular filtration rate; BNP, brain natriuretic peptide; TC, total cholesterol; PCT, procalcitonin; ECMO, extracorporeal membrane oxygenation.

\section{Acknowledgments}

This work was supported by the Fundamental Research Funds for the Central Universities (Grant No. 2020kfyXGYJ01 to P. Yin) and the National Natural Science Foundation of China (Grant No. 81570740 to X. Yu).

\section{Disclosure}

All authors report no conflicts of interest in this work.

\section{References}

1. Huang C, Wang Y, Li X, et al. Clinical features of patients infected with 2019 novel coronavirus in Wuhan, China. Lancet. 2020;395 (10223):497-506. doi:10.1016/S0140-6736(20)30183-5

2. Zhu N, Zhang D, Wang W, et al. A novel coronavirus from patients with pneumonia in China, 2019. N Engl J Med. 2020;382(8):727-733. doi:10.1056/NEJMoa2001017

3. Lu R, Zhao X, Li J, et al. Genomic characterisation and epidemiology of 2019 novel coronavirus: implications for virus origins and receptor binding. Lancet. 2020;395(10224):565-574. doi:10.1016/S0140-6736(20) 30251-8

4. Chan JF, Yuan S, Kok KH, et al. A familial cluster of pneumonia associated with the 2019 novel coronavirus indicating person-toperson transmission: a study of a family cluster. Lancet. 2020;395 (10223):514-523. doi:10.1016/S0140-6736(20)30154-9

5. Li Q, Guan X, Wu P, et al. Early transmission dynamics in Wuhan, China, of novel coronavirus-infected pneumonia. N Engl J Med. 2020.

6. Phan LT, Nguyen TV, Luong QC, et al. Importation and human-tohuman transmission of a novel coronavirus in Vietnam. $N$ Engl J Med 2020;382(9):872-874. doi:10.1056/NEJMc2001272
7. Rothe C, Schunk M, Sothmann P, et al. Transmission of 2019-nCoV infection from an asymptomatic contact in Germany. $N$ Engl J Med. 2020;382(10):970-971. doi:10.1056/NEJMc2001468

8. Wu JT, Leung K, Leung GM. Nowcasting and forecasting the potential domestic and international spread of the 2019-nCoV outbreak originating in Wuhan, China: a modelling study. Lancet. 2020;395 (10225):689-697. doi:10.1016/S0140-6736(20)30260-9

9. World Health Organization. Coronavirus disease (COVID-19) pandemic. Available from: https://www.who.int/emergencies/dis eases/novel-coronavirus-2019.

10. Chen T, Wu D, Chen H, et al. Clinical characteristics of 113 deceased patients with coronavirus disease 2019: retrospective study. BMJ. 2020;368:m1091. doi:10.1136/bmj.m1091

11. Wang $\mathrm{D}, \mathrm{Hu} \mathrm{B}, \mathrm{Hu} \mathrm{C}$, et al. Clinical characteristics of 138 hospitalized patients with 2019 novel coronavirus-infected pneumonia in Wuhan, China. JAMA. 2020;323(11):1061. doi:10.1001/jama.2020. 1585

12. Richardson S, Hirsch JS, Narasimhan M, et al. Presenting characteristics, comorbidities, and outcomes among 5700 patients hospitalized with COVID-19 in the New York City area. JAMA. 2020;323 (20):2052-2059. doi:10.1001/jama.2020.6775

13. Chen N, Zhou M, Dong X, et al. Epidemiological and clinical characteristics of 99 cases of 2019 novel coronavirus pneumonia in Wuhan, China: a descriptive study. Lancet. 2020;395(10223):507-513. doi:10. 1016/S0140-6736(20)30211-7

14. Guan WJ, Ni ZY, Hu Y, et al. Clinical characteristics of coronavirus disease 2019 in China. $N$ Engl J Med. 2020;382(18):1708-1720. doi:10.1056/NEJMoa2002032

15. Cao J, Hu X, Cheng W, et al. Clinical features and short-term outcomes of 18 patients with corona virus disease 2019 in intensive care unit. Intensive Care Med. 2020.

16. Zhang S, Diao MY, Duan L, et al. The novel coronavirus (SARS-CoV-2) infections in China: prevention, control and challenges. Intensive Care Med. 2020.

17. World Health Organization. Clinical management of severe acute respiratory infection when novel coronavirus $(2019-\mathrm{nCoV})$ infection is suspected: interim guidance. January 28, 2020. Available from: https:// www.who.int/publications-detail/clinical-management-of-severe-acuterespiratory-infection-when-novel-coronavirus-(ncov)-infection-issuspected.

18. Yang X, Yu Y, Xu J, et al. Clinical course and outcomes of critically ill patients with SARS-CoV-2 pneumonia in Wuhan, China: a single-centered, retrospective, observational study. Lancet Respir Med. 2020;8(5):475-481. doi:10.1016/S2213-2600(20)30079-5

19. Gennari FJ. Current concepts. Serum osmolality. Uses and limitations. $N$ Engl J Med. 1984;310(2):102-105. doi:10.1056/ NEJM198401123100207

20. Rohla M, Freynhofer MK, Tentzeris I, et al. Plasma osmolality predicts clinical outcome in patients with acute coronary syndrome undergoing percutaneous coronary intervention. Eur Heart J Acute Cardiovasc Care. 2014;3(1):84-92. doi:10.1177/204887261351 6018

21. Nag C, Das K, Ghosh M, et al. Plasma osmolality in acute spontanious intra-cerebral hemorrhage: does it influence hematoma volume and clinical outcome? J Res Med Sci. 2012;17(6):548-551.

22. Bhalla A, Sankaralingam S, Dundas R, et al. Influence of raised plasma osmolality on clinical outcome after acute stroke. Stroke. 2000;31(9):2043-2048. doi:10.1161/01.STR.31.9.2043

23. Öz A, Çınar T, Hayıroğlu M, et al. The predictive value of plasma osmolality for in-hospital mortality in patients with acute pulmonary embolism. Clin Respir J. 2019;13(3):174-183. doi:10.1111/ crj. 13001

24. Shen Y, Cheng X, Ying M, et al. Association between serum osmolarity and mortality in patients who are critically ill: a retrospective cohort study. BMJ Open. 2017;7(5):e015729. doi:10.1136/bmjopen2016-015729 
25. Oliveira FR, Mamede M, Bizzi MF, et al. Brown adipose tissue activity is reduced in women with polycystic ovary syndrome. Eur $J$ Endocrinol. 2019;181(5):473-480.

26. Guideline SO. KHA-CARI guideline: KHA-CARI adaptation of the KDIGO clinical practice guideline for acute kidney injury. Nephrology (Carlton). 2014;19(5):261-265. doi:10.1111/nep.12220

27. Garber AJ, Abrahamson MJ, Barzilay JI, et al. Consensus statement by the american association of clinical endocrinologists and american college of endocrinology on the comprehensive type 2 diabetes management algorithm - 2018 executive summary. Endocr Pract. 2018;24(1):91-120. doi:10.4158/CS-2017-0153

28. Baglin T. Disseminated intravascular coagulation: diagnosis and treatment. BMJ. 1996;312(7032):683-687. doi:10.1136/bmj.312. 7032.683

29. Zhou F, Yu T, Du R, et al. Clinical course and risk factors for mortality of adult inpatients with COVID-19 in Wuhan, China: a retrospective cohort study. Lancet. 2020;395(10229):1054-1062. doi:10.1016/S01406736(20)30566-3

30. Zhou J, Tan J. Diabetes patients with COVID-19 need better blood glucose management in Wuhan, China. Metabolism. 2020;107:154216. doi:10.1016/j.metabol.2020.154216

31. Bataille S, Baralla C, Torro D, et al. Undercorrection of hypernatremia is frequent and associated with mortality. BMC Nephrol. 2014;15:37. doi:10.1186/1471-2369-15-37

32. Lindner G, Funk GC, Lassnigg A, et al. Intensive care-acquired hypernatremia after major cardiothoracic surgery is associated with increased mortality. Intensive Care Med. 2010;36(10):1718-1723. doi:10.1007/s00134-010-1968-4

33. Jovanovich A, Berl T. Mortality and serum sodium in CKD-yet another U-shaped curve. Nat Rev Nephrol. 2012;8(5):261-263. doi:10.1038/nrneph.2012.65

34. Osler T, Glance LG, Hosmer DW. Complication-associated mortality following trauma: a population-based observational study. Arch Surg. 2012;147(2):152-158. doi:10.1001/archsurg.2011.888

35. Wannamethee SG, Shaper AG, Lennon L, et al. Mild hyponatremia, hypernatremia and incident cardiovascular disease and mortality in older men: a population-based cohort study. Nutr Metab Cardiovasc Dis. 2016;26(1):12-19. doi:10.1016/j.numecd.2015.07.008

36. Kruljac I, Ćaćić M, Ćaćić P, et al. The impact of hyperosmolarity on long-term outcome in patients presenting with severe hyperglycemic crisis: a population based study. Exp Clin Endocrinol Diabetes. 2018;126(9):564-569. doi:10.1055/s-0043-117416

37. Arabi YM, Mandourah Y, Al-Hameed F, et al. Corticosteroid therapy for critically ill patients with middle east respiratory syndrome. Am J Respir Crit Care Med. 2018;197(6):757-767. doi:10.1164/ rccm.201706-1172OC

38. Stockman LJ, Bellamy R, Garner P. SARS: systematic review of treatment effects. PLoS Med. 2006;3(9):e343. doi:10.1371/journal. pmed.0030343
39. Horby P, Lim WS, Emberson JR, et al. Dexamethasone in hospitalized patients with Covid-19 - preliminary report. N Engl J Med. 2020.

40. Tomazini BM, Maia IS, Cavalcanti AB, et al. Effect of dexamethasone on days alive and ventilator-free in patients with moderate or severe acute respiratory distress syndrome and COVID-19: the CoDEX randomized clinical trial. JAMA. 2020;324(13):1307-1316. doi:10.1001/jama.2020.17021

41. Song $\mathrm{Z}, \mathrm{Xu} \mathrm{Y}$, Bao L, et al. From SARS to MERS, thrusting coronaviruses into the spotlight. Viruses. 2019;11(1):59. doi:10.3390/v11010059

42. Yin Y, Wunderink RG. MERS, SARS and other coronaviruses as causes of pneumonia. Respirology. 2018;23(2):130-137. doi:10.1111/ resp. 13196

43. Mahase E. Coronavirus covid-19 has killed more people than SARS and MERS combined, despite lower case fatality rate. $B M J$. 2020;368:m641. doi:10.1136/bmj.m641

44. Young BE, Ong SWX, Kalimuddin S, et al. Epidemiologic features and clinical course of patients infected with SARS-CoV-2 in Singapore. JAMA. 2020;323(15):1488. doi:10.1001/jama.2020. 3204

45. Arentz M, Yim E, Klaff L, et al. Characteristics and outcomes of 21 critically ill patients with COVID-19 in Washington State. JAMA. 2020;323(16):1612. doi:10.1001/jama.2020.4326

46. Chu H, Zhou J, Wong BH, et al. Middle East respiratory syndrome coronavirus efficiently infects human primary $\mathrm{T}$ lymphocytes and activates the extrinsic and intrinsic apoptosis pathways. $J$ Infect Dis. 2016;213(6):904-914. doi:10.1093/infdis/jiv380

47. Gu J, Gong E, Zhang B, et al. Multiple organ infection and the pathogenesis of SARS. $J$ Exp Med. 2005;202(3):415-424. doi:10.1084/jem.20050828

48. Zhang JJ, Dong X, Cao YY, et al. Clinical characteristics of 140 patients infected with SARS-CoV-2 in Wuhan, China. Allergy. 2020;75(7):1730-1741. doi:10.1111/all.14238

49. Mahallawi WH, Khabour OF, Zhang Q, et al. MERS-CoV infection in humans is associated with a pro-inflammatory Th1 and Th17 cytokine profile. Cytokine. 2018;104:8-13. doi:10.1016/j.cyto.2018. 01.025

50. Wong CK, Lam CW, Wu AK, et al. Plasma inflammatory cytokines and chemokines in severe acute respiratory syndrome. Clin Exp Immunol. 2004;136(1):95-103.

51. Ruan Q, Yang K, Wang W, et al. Clinical predictors of mortality due to COVID-19 based on an analysis of data of 150 patients from Wuhan, China. Intensive Care Med. 2020.

\section{Publish your work in this journal}

Diabetes, Metabolic Syndrome and Obesity: Targets and Therapy is an international, peer-reviewed open-access journal committed to the rapid publication of the latest laboratory and clinical findings in the fields of diabetes, metabolic syndrome and obesity research. Original research, review, case reports, hypothesis formation, expert opinion and commentaries are all considered for publication. The manuscript management system is completely online and includes a very quick and fair peer-review system, which is all easy to use. Visit http://www.dovepress.com/testimonials.php to read real quotes from published authors. 